\title{
Violência simbólica na formação de professores de Ciências e Biologia: julgamentos de bens simbólicos do subcampo da escola
}

\section{Symbolic violence in the Science and Biology teachers: the assessment of symbolic goods in the school subfield}

Ana Cecília Mello'

iD Ivanilda Higa²

\author{
'Universidade Federal do Paraná (UFPR), Curitiba, PR, Brasil. \\ Autora correspondente: ana.mello@ufpr.br \\ ¿Universidade Federal do Paraná (UFPR), Setor de Educação, Departamento de Teoria e Prática de Ensino, \\ Curitiba, PR, Brasil.
}

Resumo: Este trabalho objetiva compreender o Desenvolvimento Profissional Docente de estagiários da Licenciatura em Ciências Biológicas de um subcampo da universidade por meio da análise dos julgamentos conferidos por estes aos bens simbólicos de um subcampo da escola. Com abordagem qualitativa, são realizadas entrevistas com quatro estagiários, identificando-se os bens simbólicos do subcampo da escola e os referidos julgamentos. Percebe-se que ocorre a desvalorização das produções culturais e simbólicas do subcampo escolar e da escola frente às do subcampo universitário, assim como a desvalorização da profissão do subcampo da escola e desse próprio subcampo. Frente a isso, depreende-se que - estágio supervisionado pode configurar uma relação de violência simbólica e, para superar essa situação, sugere-se focalizar a profissão docente do subcampo da escola durante o estágio de uma forma mais ampla, assim como a implementação de parcerias colaborativas entre os subcampos.

Palavras-chave: Estágio supervisionado; Ensino de biologia; Ensino de ciências; Violência simbólica.

Abstract: This research aims to explain the Professional Development of Science and Biology Teachers as undergraduate interns in a subfield of the university, through the analysis of their assessment of symbolic goods in a subfield of the school. With a qualitative approach, interviews were carried out with four interns, identifying the symbolic goods in the school subfield and their corresponding judgments. Results indicate the devaluation of cultural and symbolic productions of the school subfield and of the school in the face of the university, as well as the devaluation of the school subfield profession and that subfield itself. Considering these results, it is understood that the supervised internship can represent a form of symbolic violence and, to overcome this situation, it is suggested that the focus on the teachers' profession of the school subfield should be broader, to implement collaborative partnerships among the subfields.

Keywords: Supervised internship; Science teaching; Biology teaching; Symbolic violence.

Recebido em: 06/01/2021

Aprovado em: 05/08/2021 


\section{Introdução}

A formação inicial de professores da Educação Básica no Brasil articula dois subcampos do campo educacional brasileiro (GENOVESE, 2014): o subcampo escolar e o universitário.

O campo educacional brasileiro é composto pelos seguintes subcampos: campo da confederação e federação dos profissionais da educação; campo universitário, no interior do qual estão os subcampos ligados ao ensino de ciências, a saber, o campo acadêmico e o campo científico educacional em ensino de ciências; campo das secretarias de educação (ligadas aos governos federal, estadual e municipal); e campo escolar (GENOVESE, 2014, p. 65, grifo nosso).

Essa articulação entre os dois subcampos se torna evidente durante o estágio supervisionado, momento no qual os estudantes de Licenciatura experienciam o subcampo escolar e, devido a diferentes fatores, é considerado relevante para o Desenvolvimento Profissional Docente (DPD) (DAY, 2005) de futuros professores e para os professores do subcampo da escola que orientam esses estagiários (professor supervisor) (MELLO, 2015). Ao longo deste trabalho, adota-se o termo 'professor supervisor' para se referir ao professor do subcampo da escola que orienta os estagiários e 'professor orientador' ao professor do subcampo da universidade responsável pela disciplina de Estágio Supervisionado ou Prática de Ensino, em observação à Lei dos Estágios (BRASIL, 2008).

No subcampo escolar o professor supervisor é importante na formação dos estagiários, como descrito em diferentes estudos (AROEIRA, 2014; CALDERANO, 2017; LIMA, 2012; VAILLANT; MARCELO GARCIA, 2012, entre outros). Confere-se a esse agente a importância de inserir o futuro professor no subcampo da escola, onde atuará profissionalmente, evidenciando, por exemplo, elementos do habitus daquele grupo (GENOVESE; CASTILHO; QUEIROZ, 2015). Além disso, o estágio possibilita ao estagiário a percepção das disputas e dos capitais daquele subcampo, promovendo também o contato dos estagiários com os diferentes bens simbólicos (BOURDIEU, 2003) do subcampo escolar.

Os estagiários, por sua vez, emitem julgamentos a respeito dos bens simbólicos do subcampo escolar com os quais entram em contato no momento de estágio supervisionado mediado, principalmente, pelos professores supervisores de estágio. Assim, pergunta-se: o que a análise desses julgamentos nos permite inferir a respeito da formação docente inicial?

Este estudo, por meio da análise desses julgamentos, aponta para a possibilidade de se compreender, ao menos em parte, a formação docente no seu processo, uma vez que esses julgamentos assinalam para a concepção do que seria a 'profissão docente' do subcampo escolar e do que seria 'escola', ambos entendimentos desenvolvidos ao longo da vida de um professor, mas de forma mais intensa durante a Licenciatura.

Nesse sentido, tem-se como objetivo compreender parte do processo de DPD dos estagiários, estudando especificamente os julgamentos conferidos por estagiários da Licenciatura em Ciências Biológicas de um subcampo universitário (composto por uma universidade pública) aos bens simbólicos de um subcampo da escola. Acredita-se que esses julgamentos estejam atrelados a uma relação de violência simbólica entre os subcampos envolvidos na formação docente inicial. 
A violência simbólica se estabelece por meio do arbitrário cultural (BOURDIEU; PASSERON, 2012) de agentes sobre os outros ou de subcampos sobre os outros, ou seja, por meio da imposição de representações entre estes e do irreconhecimento dessa imposição e adesão a essas representações por parte dos dominados (MAUGER, 2017).

Entende-se que todo esse processo no desenvolvimento do estágio supervisionado na formação de professores envolve a relação entre diferentes agentes (professor orientador, licenciandos, professor supervisor, estudantes e outros indivíduos) e instituições (escolas, universidades, mantenedoras) e que é neste diálogo que o licenciando vai realizando julgamentos, hierarquizações e vai construindo seu DPD. No entanto, neste trabalho, atenta-se para o estagiário e a construção de seus julgamentos a respeito dos subcampos da escola e escolar. Para maiores aprofundamentos dessa discussão recomenda-se a leitura do trabalho do qual deriva este presente artigo (MELLO, 2019), no qual são discutidos também os julgamentos conferidos aos bens simbólicos do subcampo universitário pelos estagiários, assim como os julgamentos conferidos pelos professores do subcampo da escola a seu próprio subcampo.

\section{Estágio supervisionado como desenvolvimento profissional docente}

A formação de professores no Brasil foi estabelecida como competência das Faculdades de Educação pelo Decreto-lei no 1.190 de 4 de abril de 1939 (SAVIANI, 2007). Contudo, até a década de 1970, a formação docente brasileira ocorria em dois âmbitos principais: formação de professores da escola primária, nas Escolas Normais (PIMENTA, 2006) e para a escola secundária e Escolas Normais, nas Escolas de Professores, Institutos de Educação e Faculdades de Educação das universidades brasileiras.

Essa formação se baseava na relação intrínseca com as escolas, denominadas escolas de experimentação, tanto no Ensino Normal atrelado às instituições de Educação Básica (PIMENTA, 2006), quanto nas Escolas de Professores e Institutos de Educação em relação às escolas de experimentação (SAVIANI, 2007).

Contudo, "[...] ao ser generalizado, o modelo de formação de professores em nível superior perdeu sua referência de origem, cujo suporte eram as escolas experimentais às quais competia fornecer uma base de pesquisa que pretendia dar caráter científico aos processos formativos." (SAVIANI, 2007, p. 116-117). Da mesma forma, com a promulgação da Lei 5.692 (BRASIL, 1971) houve um desmantelamento das Escolas Normais, passando a formação de professores desse nível a ser mais uma habilitação profissional presente no que hoje se denomina Ensino Médio.

A partir daí, muitas instituições de Ensino Médio ofertaram a habilitação de Magistério sem, contudo, possuir estrutura para tal. Por sua vez, Escolas Normais começaram a ofertar outras habilitações profissionais. Segundo Pimenta (2006), esse foi um dos fatores que descaracterizou a formação docente, agora substancialmente dissociada da realidade escolar, e por isso, mais precária dada a sua oferta por faculdades ao longo da década de 1980.

Nesse sentido, a separação entre a formação no curso de Ensino Normal, Institutos e Faculdades de Educação - ou, atualmente, nos cursos das diferentes licenciaturas - e a carreira profissional desse docente configura o contexto no qual o estágio supervisionado se desenvolveu e se encontra nos dias atuais. 
Assim, de acordo com Pimenta (2006), houve um acirramento na separação entre teoria e prática com o desmantelamento do Ensino Normal em 1970, que já vinha ocorrendo desde o final da década de 1930. Considera-se que a dissociação entre teoria e prática nos cursos de formação docente possa ter sofrido influência da concepção tradicional de formação de professores (MARCELO GARCIA, 1999). Como desdobramentos dessa concepção, amplamente difundida, há a separação entre a formação docente inicial, a continuada e o exercício da profissão propriamente dito.

Além disso, segundo Saviani (2007), durante a história de formação de professores no Brasil houve a disputa entre uma formação centrada no ensino, protagonizada pelo professor e pela teoria (concepção tradicional) e uma formação centrada na aprendizagem, com foco no aluno e na prática (concepção construtivista). Isso contribuiu para essa cisão entre teoria e prática. Assim, ao separar a formação da profissão é de se esperar que o momento do aprendizado teórico seja separado do prático, este sendo atribuído, majoritariamente, ao estágio.

Por outro lado, há uma concepção de formação docente divergente da tradicional no que diz respeito à separação entre teoria e prática. Contudo, ressalta-se, ambas compartilham o entendimento do professor envolvendo-se em processos formativos para aprender, melhorar enquanto profissional e aumentar a qualidade do ensino para o aluno (MARCELO GARCIA, 1999).

Essa concepção engloba diferentes entendimentos de formação que atribuem centralidade à profissão docente e, por isso, não separa a formação inicial da continuada e ambas do exercício profissional, assim como a teoria da prática. Esse conceito, denominado DPD, procura ampliar a perspectiva da formação do professor, incluindo diferentes processos formativos e aspectos de sua carreira. Assim, considera-se o DPD como:

[...] um processo contínuo que tem início antes de ingressar na licenciatura, estende-se ao longo de toda sua vida profissional e acontece nos múltiplos espaços e momentos da vida de cada um, envolvendo aspectos pessoais, familiares, institucionais e socioculturais (FIORENTINI, 2008, p. 45 apud FIORENTINI; CRECCI, 2013, p. 13).

Dessa forma, compreendendo a formação docente como DPD, a associação entre teoria e prática é mais viabilizada, uma vez que todos os momentos 'teóricos'e 'práticos' se configuram como um processo amplo, contínuo e abrangente de formação, do qual fazem parte momentos de aprendizagem enquanto estudantes, aspectos da vida pessoal, especificidades referentes ao momento de carreira, aprendizagens informais entre professor, alunos e colegas, entre outros diversos momentos e aspectos (DAY, 2005).

Nesse sentido, o estágio supervisionado insere-se nesse contínuo DPD, sendo um momento de formação formal (CHANTRAINE-DEMAILLY, 1995), por integrar o currículo de formação docente do estagiário da licenciatura e também momento de formação informal (CHANTRAINE-DEMAILLY, 1995) tanto para esse estagiário quanto para o professor supervisor do subcampo da escola (MELLO, 2015; MELLO; HIGA, 2018). Entende-se como formação informal a 
em situação (a maneira como os professores aprendem a sua profissão, solicitando conselhos e truques aos seus colegas, observando-os a trabalhar e imitando-os, é um processo de formação informal) (CHANTRAINE-DEMAILLY, 1995, p. 142).

Durante o estágio supervisionado, nessa aprendizagem informal, o estagiário pode construir seu entendimento da escola agora como local de exercício da profissão (antes como instituição da qual foi aluno, quando já eram construídas suas referências como futuro professor), ao mesmo tempo que desenvolve o seu entendimento sobre o agente profissional professor. Ou seja, desenvolve-se professor a partir da compreensão da escola como eixo central para sua profissionalidade.

Nesse sentido, essa aprendizagem com os professores supervisores caracterizase como uma aprendizagem de extrema relevância na compreensão de sua formação como DPD. Dessa forma, nesse momento inicia-se a construção do habitus docente, do entendimentos do funcionamento das leis dos subcampos e da compreensão dos capitais em disputa nos mesmos: aspectos que serão aprofundados continuamente ao longo de sua vida profissional.

Esses aspectos são produções características do subcampo da escola (GENOVESE, 2014) e são, portanto, bens simbólicos (BOURDIEU, 2003). Tais bens simbólicos são apreendidos, portanto, pelos estagiários, de forma mais intensa, na vivência no subcampo da escola e com seus agentes - os professores supervisores. Assim, atentase, neste trabalho, para os bens simbólicos que permitem caracterizar a profissão docente da Educação Básica e seu local de exercício profissional: os subcampos escolar e da escola.

\section{Estagiários como agentes híbridos e classificadores de bens simbólicos}

Para compreender as produções de ordem cultural e simbólica do subcampo da escola presentes no DPD dos estagiários como futuros professores da Educação Básica, parte-se do entendimento da organização da realidade social em campos sociais (BOURDIEU, 1983).

Nesta perspectiva, a escola está imbricada em interesses, habitus, disputas e capitais de seus agentes (os professores da escola) e pertence, junto às demais escolas de Educação Básica, ao campo educacional brasileiro (GENOVESE, 2014). Como um subcampo, portanto, possui leis, habitus e capitais próprios que a individualizam como tal e, ao mesmo tempo, compartilha leis, habitus e capitais com as demais escolas do campo educacional, compondo o subcampo escolar. As disputas por capitais no seu interior implicam em diferentes posições ocupadas por seus agentes, resultando em prestígio diferenciado entre eles.

Como tal, o subcampo da escola por meio de seus agentes produz bens culturais e, ao mesmo tempo, simbólicos, que propiciam a comunicação entre os agentes, a sua dominação e hierarquização. Por sua vez,

Os símbolos são os instrumentos por excelência da "integração social": enquanto instrumentos de conhecimento e de comunicação [...], eles tornam possível o consensus acerca do sentido do mundo social que contribui fundamentalmente para a reprodução da ordem social: a integração "lógica" é a condição da integração "moral". (BOURDIEU, 2003, p. 10, grifos do autor). 
Nesse sentido, os agentes dos diferentes campos, inclusive do subcampo da escola, imersos na sua organização com leis, habitus, capitais, disputas e hierarquizações, procuram valorizar seu subcampo por meio dos bens simbólicos, 'impondo suas verdades', suas lógicas aos demais subcampos, “[...] aos outros agentes do campo (ou de outros) de modo dissimulado e natural, ou seja, dominando-os por meio da violência simbólica". (BOURDIEU; PASSERON, 1992 apud GENOVESE, 2014, p. 65, grifo nosso).

Além disso, nos diferentes campos sociais, os bens simbólicos possuem uma relação implícita com a estratificação por classes sociais (econômica, política e cultural). Nesse sentido, há relações de homologia entre os diferentes campos e o campo do poder e, com isso, as lutas internas por classificações dos bens simbólicos produzidos pelos diferentes campos representam transformações das disputas entre as classes sociais: "Assim, a luta de classificações é uma dimensão, mas, sem dúvida, a mais bem oculta da luta de classes." (BOURDIEU, 2015, p. 160).

As diferentes classes e fracções [sic] de classe estão envolvidas numa luta propriamente simbólica para imporem a definição do mundo social mais conforme aos seus interesses, e imporem o campo das tomadas de posições ideológicas reproduzindo em forma transfigurada o campo das posições sociais (BOURDIEU, 2003, p. 11).

Os bens simbólicos são produções culturais, desempenham papéis simbólicos, ou seja, de classificação e hierarquização (BOURDIEU, 2003) e são de ordem variada, podendo se relacionar, por exemplo, no caso dos subcampos em questão, ao entendimento da profissão docente: suas atribuições, seu habitus, ou à relação com o conhecimento desenvolvida na atividade docente.

O estagiário, estudante de licenciatura em Ciências Biológicas, por não ser profissional, não pertence ainda a nenhum subcampo e é considerado um agente 'híbrido', circulando entre o subcampo da universidade e o da escola (PASSIANI; ARRUDA, 2017). O estágio propicia, assim, um momento e espaço híbridos entre os dois subcampos, por meio do qual o estagiário entra em contato com os bens simbólicos produzidos por ambos, julgando-os, classificando-os e promovendo sua circulação com sua movimentação entre os mesmos.

Vista sob a perspectiva do conceito de DPD, a profissão representa um eixo essencial na formação docente. Nesse sentido, os bens simbólicos produzidos pelos agentes do subcampo da escola a respeito de sua profissão e de seu subcampo (local de atuação profissional) adquirem também centralidade para a compreensão do DPD desses estagiários. Assim, ao se identificar esses bens simbólicos, esperase compreender o entendimento a respeito dos agentes do subcampo da escola (os professores), o habitus em questão, os capitais e as disputas que caracterizam tal subcampo.

Por outro lado, ao desenvolverem seus julgamentos a respeito desses bens simbólicos em contraposição aos bens simbólicos produzidos no subcampo da universidade - que refletem a profissionalidade daquele subcampo em específico -, os estagiários evidenciam hierarquizações e identificações com um ou outro subcampo e podem sinalizar de que maneira esse DPD está sendo construído naquele momento. 
Em última análise, os julgamentos dos estagiários a respeito dos bens simbólicos do subcampo escolar e da escola indicam a maneira como a profissionalidade do docente da Educação Básica está sendo construída.

Dessa forma, na movimentação entre os subcampos, os estagiários desenvolvem seus julgamentos a respeito dos bens simbólicos com os quais entram em contato, consumindo-os (LAHIRE, 2002), classificando-os e hierarquizando-os, ao mesmo tempo em que esse julgamento recai sobre os subcampos e seus agentes produtores. Por meio dessa classificação, uma identificação com esses subcampos é construída entre os estagiários, valorizando um e/ou outro, ou seja, pode-se perceber o desenvolvimento precoce da illusio pelos subcampos.

A illusio pode ser entendida como o interesse tácito dos agentes em participar da lógica daquele campo, refletido na crença e no investimento no mesmo, e cada uma é específica de determinado campo, pois este "[...] requer e aciona uma forma de interesse, um investimento, uma illusio específica" (BOURDIEU, 1992, p. 93 apud AGUIAR, 2017, p. 231). Nesse sentido, a illusio que um agente estabelece com um campo "[...] significa reconhecer ali alvos dignos de serem perseguidos. [...] um produto e princípio das ações práticas próprias a um espaço social delimitado, e menos como resultante de um cálculo racional que prevê lucros." (AGUIAR, 2017, p. 231).

Essa ilusão necessária sobre si mesmo e sobre o mundo decorre exatamente da adesão ao conjunto de dogmas implícitos, crenças fundamentais, enfim à mesma doxa, que veicula os valores daquele universo, determina o que é importante, as apostas em jogo, ou o que deve ser negligenciado (AGUIAR, 2017, p. 232).

Assim, o licenciando, de maneira não consciente, não intelectualizada e não explícita, desenvolve durante todo o seu DPD e, acredita-se, mais intensamente durante o estágio supervisionado, sua illusio com algum dos subcampos do campo educacional brasileiro, reconhecendo seus bens simbólicos e, como consequência dessa illusio, os classificando, estabelecendo julgamentos sobre os mesmos e sobre os respectivos subcampos e seus agentes.

\section{Objetivos}

Objetiva-se compreender parte do processo formativo experimentado durante o estágio supervisionado por estagiários de licenciatura em Ciências Biológicas de uma universidade pública por meio da análise dos julgamentos por eles atribuídos aos bens simbólicos de um subcampo da escola.

Para alcançar tal objetivo, procede-se: (a) a identificação desses bens simbólicos, sendo selecionados prioritariamente aqueles que dizem respeito à profissão docente da Educação Básica e ao subcampo escolar; (b) a análise e compreensão do julgamento conferido pelos estagiários a esses bens simbólicos, e (c) análise da relação entre esses julgamentos e o DPD vivenciado. 


\section{Aspectos metodólogicos}

Este trabalho é derivado de uma pesquisa com abordagem qualitativa com o interesse nos significados atribuídos pelos agentes à realidade (LESSARD-HÉBERT; GOYETT; BOUTIN, 2012). Neste caso, os agentes sociais são os estagiários e a realidade, o subcampo da escola e escolar e a profissão docente. Como ferramenta metodológica utiliza-se a entrevista, entendendo-a como uma relação social (BOURDIEU, 2001) e, portanto, sendo limitada por um lado, ao mesmo tempo em que, por outro lado, apresenta relevância à compreensão dos significados atribuídos pelos agentes à realidade.

Nesse sentido, no intuito de aproximar-se dos estagiários da licenciatura em Ciências Biológicas que escolheram o subcampo da escola investigado e compreender os bens simbólicos do subcampo universitário a respeito da profissão docente, acompanhou-se, durante um ano letivo da universidade, a disciplina de Prática de Ensino (ou estágio supervisionado) do curso de Licenciatura em Ciências Biológicas do período diurno da universidade do subcampo universitário analisado.

A disciplina é obrigatória para a modalidade de licenciatura, sendo ofertada para alunos dos $9^{\circ}$ e $10^{\circ}$ períodos do curso de maneira anual (com duração de dois semestres letivos). A sua proposta é organizar os estagiários em duplas para sua inserção no subcampo da escola. Essa inserção ocorre em três momentos: (1) No primeiro semestre, Observação e preparação para a Intervenção; (2) A Intervenção no primeiro semestre; (3) Período de Regência durante o segundo semestre. ${ }^{1}$

Assim, foram selecionados quatro estagiários organizados, portanto, em duas duplas, para colaborar com a investigação. Ao longo de um ano foram realizadas três entrevistas individuais com cada um dos quatro estagiários, além de duas entrevistas com os dois estagiários das duas duplas ao mesmo tempo. Dessa forma, há um total de 16 entrevistas. Os estagiários concordaram, espontaneamente, em participar da pesquisa, acordando a sua participação no Termo de Consentimento Livre e Esclarecido no qual foi evidenciado o objetivo da pesquisa, a sua realização e as contribuições que sua participação poderia gerar, assim como se destacou que, a qualquer momento, os mesmos poderiam requerer a retirada de sua participação na investigação.

Os estagiários foram selecionados por terem escolhido para estágio a escola na qual já era desenvolvida a investigação. No quadro 1 seguinte apresenta-se o perfil de cada um, no qual se observa que, dos quatro, três estavam envolvidos em iniciação científica na área do bacharelado, área de prestígio no campo da universidade investigada; dois deles manifestaram que gostariam de ser professores da Educação Básica e dois eram filhos de professores do subcampo universitário (em outra universidade que não a pesquisada), sendo que um destes é filho de professora do subcampo escolar.

\footnotetext{
'A intervenção teve como objetivo trabalhar com demandas dos alunos e dos professores do subcampo da escola, levantadas por meio da observação realizada pelos estagiários, da aplicação de um questionário com os estudantes e do diálogo com o professor supervisor. A intervenção deveria ser pontual e realizada preferencialmente de forma lúdica, como por exemplo, uma oficina, não sendo necessário obedecer ao currículo previsto pelo professor. A intervenção difere da regência, pois esta ocorreu durante grande parte do segundo semestre, de maneira contínua e integrada ao currículo e cronograma escolar.
} 
Quadro 1 - Informações sobre os estagiários

\begin{tabular}{|l|c|l|c|l|l|l|}
\hline Estagiários & Idade & \multicolumn{1}{|c|}{$\begin{array}{c}\text { Educação } \\
\text { Básica }\end{array}$} & $\begin{array}{c}\text { Identificação } \\
\text { com o SE }\end{array}$ & Profissão do pai & Profissão da mãe & $\begin{array}{l}\text { Atividades na } \\
\text { universidade }\end{array}$ \\
\hline Estagiária 1 & 22 & $\begin{array}{l}\text { Pública } \\
\text { privada }\end{array}$ & Não & Contador & Serviços & IC na área do Bacharelado \\
\hline Estagiário 2 & 23 & Privada & Sim & Professor do SU & Professora do SE & IC na área do Bacharelado \\
\hline Estagiária 3 & 21 & Pública & Sim & Segurança & $\begin{array}{l}\text { Laboratorista de } \\
\text { Análises Clínicas }\end{array}$ & IC na área do Bacharelado \\
\hline Estagiária 4 & 22 & Privada & Não & Professor do SU & Engenheira civil & $\begin{array}{l}\text { Monitoria em Educação } \\
\text { Ambiental }\end{array}$ \\
\hline
\end{tabular}

Legenda: SE = Subcampo escolar; SU = Subcampo universitário; IC = Iniciação Científica.

Fonte: adaptado de Mello (2019).

O subcampo da escola investigado é um colégio estadual com bastante prestígio no subcampo escolar pela sua longevidade, estrutura física e outros aspectos. Nos anos de 2017 e 2018, a escola possuía 14 professores da área de Ciências e Biologia nos três turnos, entre efetivos e substitutos. A investigação (MELLO, 2019) teve a colaboração de 10 professores entrevistados (média de duas entrevistas por professor), além de observações das reuniões de coordenação da área de Ciências e Biologia. Entretanto, dentre esses professores, apenas duas eram supervisoras das duplas de estagiários selecionadas e, portanto, procedeu-se com um número maior de entrevistas com essas duas professoras (além das duas primeiras, mais duas entrevistas com cada uma, totalizando seis entrevistas com as duas professoras).

A relação com o subcampo universitário investigado se deu por meio do acompanhamento durante um ano letivo da disciplina anteriormente referida, não sendo focalizado, naquele momento, o subcampo por completo, uma vez que o foco era os estagiários. Trata-se de uma universidade pública que oferta diferentes licenciaturas, dentre elas a de Ciências Biológicas tanto no período diurno quanto noturno. Uma caracterização mais completa dos subcampos está presente em Mello (2019).

Para preservar a identidade de cada estagiário, será usada a denominação Estagiário 1, 2, 3 e 4. Da mesma forma será feito com os professores supervisores aos quais os estagiários eventualmente se refiram. As entrevistas foram realizadas durante todo o ano letivo da disciplina em diferentes momentos: (1) Entrevistas individuais durante a Observação na escola; (2) Entrevista com as duplas Pré-intervenção; (3) Entrevista com as duplas Pós-intervenção; (4) Entrevistas individuais Pré-regência; (5) Entrevistas individuais Pós-regência.

\section{Resultados: os bens simbólicos do subcampo da escola e os julgamentos atribuídos pelos estagiários}

As entrevistas com os estagiários tiveram como objetivos perceber a sua compreensão a respeito da profissão docente da Educação Básica vivenciada por eles durante o estágio supervisionado. Dessa forma, procurou-se identificar como os estagiários percebiam a rotina do professor supervisor, sua relação com os alunos do subcampo da escola, sua relação com seus colegas professores, com a direção da

\footnotetext{
${ }^{2}$ Avaliou-se se, explicitamente durante as entrevistas, os estagiários gostariam de ser professores da Educação Básica, o que se classificou como 'Identificação com o subcampo escolar'.

${ }^{3}$ Atividades com as quais os estagiários estavam envolvidos no curso no momento da pesquisa.
} 
escola, com o conhecimento escolar, com o tempo, entre outros fatores, além dos avaliados pelos estagiários como próprios do professor do subcampo escolar e da escola. Além disso, para ressaltar esse caráter próprio do subcampo da escola aferido a esses elementos pelos estagiários, as perguntas tiveram como propósito perceber se há uma comparação com sua vivência no subcampo universitário, distinguindo os professores desses subcampos.

A esses elementos produzidos pelos agentes do subcampo da escola e que caracterizam a profissão docente da Educação Básica percebidos pelos estagiários denominou-se bens simbólicos (BORDIEU, 2003). Estes foram organizados em categorias e subcategorias que indicam a natureza da caracterização da profissão do professor dos subcampos escolar e da escola.

Portanto, foram assim categorizados: Relação com o conhecimento escolar; Relação com os alunos; e Habitus do Homo magister. O quadro 2 sintetiza os bens simbólicos identificados nas entrevistas dos estagiários por meio de suas categorias e subcategorias.

Quadro 2 - Bens simbólicos dos subcampos escolar e da escola a partir das entrevistas com os estagiários

\begin{tabular}{|c|c|c|}
\hline Categorias & Subcategorias & Bens simbólicos \\
\hline \multirow{13}{*}{$\begin{array}{l}\text { Relação com o conhecimento } \\
\text { escolar }\end{array}$} & \multirow{5}{*}{$\begin{array}{l}\text { Os alunos da escola e os bens culturais } \\
\text { da escola }\end{array}$} & Relação dos alunos com as disciplinas \\
\hline & & O lúdico na aprendizagem \\
\hline & & O tipo de conhecimento para os alunos \\
\hline & & Habilidades e aprendizagens diversas \\
\hline & & Maneiras de despertar o interesse dos alunos \\
\hline & Os bens culturais do subcampo da escola & Os bens culturais do subcampo escolar \\
\hline & \multirow[t]{7}{*}{ Organização dos Bens culturais da escola } & $\begin{array}{l}\text { Sistematização, formato das aulas, diferentes } \\
\text { estratégias e recursos }\end{array}$ \\
\hline & & Currículo escolar \\
\hline & & Uso do livro didático \\
\hline & & $\begin{array}{l}\text { Atividades que permitem o acompanhamento } \\
\text { dos alunos de forma contínua }\end{array}$ \\
\hline & & Avaliação \\
\hline & & Folheto de planejamento de conteúdos \\
\hline & & Trabalho visando o vestibular e o ENEM \\
\hline \multirow[t]{5}{*}{ Relação com os alunos } & \multirow[t]{3}{*}{ Relação Interpessoal } & Conversa com os alunos \\
\hline & & Proximidade \\
\hline & & Cuidado e atenção com os alunos \\
\hline & \multirow[t]{2}{*}{ Aprendizagem } & Uso de exemplos pessoais para aprendizagem \\
\hline & & Controle de Comportamento \\
\hline \multirow[t]{6}{*}{ Habitus do Homo magister } & \multirow[t]{2}{*}{ Relação com o tempo } & Adequação das aulas ao tempo escasso \\
\hline & & Administração do tempo de sala de aula \\
\hline & \multirow[t]{4}{*}{ Atribuições } & $\begin{array}{l}\text { Preparo de aula, desenvolvimento de aula, } \\
\text { correção de atividades }\end{array}$ \\
\hline & & Imprevistos \\
\hline & & Adequação ao currículo escolar \\
\hline & & Atenção em várias coisas ao mesmo tempo \\
\hline
\end{tabular}

Fonte: elaborado pelas autoras. 
Na sequência proceder-se-á, em cada uma das três categorias, à análise e compreensão do julgamento conferido pelos estagiários aos bens simbólicos. Ressaltase que a discussão foi mais detalhada neste trabalho a respeito dos bens simbólicos, entendendo-se que tenham maior relação com a profissão docente e com a formação docente dos estagiários e, também, que exemplificam as categorias e subcategorias de análise. Estes estão destacados em negrito no quadro 2. Um maior detalhamento dos bens simbólicos está presente em Mello (2019).

\section{Relação com o conhecimento escolar}

A maneira como o professor organiza seu objeto de trabalho - o conhecimento escolar -, segundo os estagiários, permite que a aprendizagem dos estudantes seja eficaz se for mais lúdica. Assim, as diferentes maneiras como o professor organiza esse conhecimento foram agrupadas nesta categoria: Relação com o Conhecimento Escolar.

Nesse sentido, os estagiários destacam diferentes estratégias, técnicas e recursos didáticos utilizados pelos professores supervisores como jogos, slides, cronograma de aulas, processos de avaliações contínuas, arte no ensino, uso do livro didático, utilização de banners e modelos didáticos, o trabalho visando o ingresso no Ensino Superior por meio de exercícios de vestibular e do Exame Nacional do Ensino Médio (ENEM), entre outros que, de acordo com seu julgamento, mediam a aprendizagem dos alunos.

Por outro lado, também se faz presente um julgamento, por parte dos estagiários, a respeito do conhecimento escolar, caracterizando-o como obsoleto, superficial e, por isso, para seu trabalho não seria necessário maior aprofundamento do já presente nos livros didáticos utilizados pelos professores.

Porque, por exemplo, eu sei que é muito importante para a formação dos alunos certas coisas. Mas às vezes até o conteúdo aqui da escola, os professores acham que está obsoleto, todo mundo acha que está obsoleto. Só que não muda, né? Porque está tudo no mesmo currículo ali. Então, pra mim, ficar só estudando para dar aquelas aulas às vezes perde o sentido. Às vezes eu quero um projeto maior, eu quero aliar o meu ideal de ajudar a formação de um ser humano enquanto ser humano na escola, mas eu também tenho ideais de mudar outras coisas. [Estagiária 4, Momento de Observação, Pergunta referente a sua motivação enquanto professora].

Ainda a esse respeito, um dos estagiários avalia, por exemplo, que não há necessidade que o professor do subcampo escolar aprofunde a preparação de suas aulas com outro conteúdo além do presente nos livros didáticos, pois este seria o tipo de conhecimento ao qual o aluno da Educação Básica está preparado para entrar em contato. Esse julgamento é realizado de forma comparativa com os bens culturais e simbólicos do subcampo universitário, ocorrendo, portanto, uma hierarquização entre os mesmos e seus respectivos subcampos.

Sim é o livro didático deles, conteúdo que eles precisam saber, que eles precisam dominar. Não vou perder tempo de pegar um livro da faculdade para passar para eles. [Estagiário 2, Momento Pósregência, Pergunta referente a como preparava as aulas da regência]. 
Além disso, os estagiários percebem a maneira por meio da qual os alunos da escola se relacionam com o conhecimento escolar. Segundo eles, os alunos necessitam que a interdisciplinaridade seja desenvolvida pelos professores, pois os alunos não conseguem fazer essa relação entre as disciplinas por si próprios. Observam, também, que a aprendizagem ocorre de diferentes maneiras e, ainda, para alguns estagiários, os professores devem procurar atingir essas diferentes aprendizagens, por isso a preocupação em desenvolver recursos didáticos variados, investindo na ludicidade.

\section{Relação com os alunos}

Outra produção simbólica dos subcampos escolar e da escola é a relação estabelecida pelos professores com seus alunos. Os estagiários julgam esta relação como de proximidade e cuidado com os alunos e objetivando a sua aprendizagem.

O julgamento a respeito desta relação é estabelecido por meio da contraposição com a relação que o professor do subcampo universitário estabelece com seus alunos. Conforme destaca Genovez (2008), para o subcampo escolar esta relação estabelecida com os alunos configura-se como uma estratégia para maior obtenção de capital docente. Por sua vez, no subcampo universitário, a centralidade nas disputas por capitais reside nas atividades de pesquisa (PEREIRA, 2000), sendo a relação com o ensino e com os alunos atividades estrategicamente secundárias.

Nessa perspectiva, a relação com os alunos adquire um valor maior para os professores do subcampo escolar, estabelecendo conversas mais próximas, fazendo uso de exemplos de sua vida pessoal para atrair a atenção e a empatia dos alunos e organizando o conteúdo de suas aulas baseando-se nessa relação.

Por exemplo quando você vê que os alunos estão bagunçando, assim, aí teve um dia que ela [a professora 6] falou: 'Vamos parar aqui, deixa eu contar uma história para vocês aqui'. Daí ela falou um negócio lá da vida dela, sabe? Para quebrar o clima, assim. [...] Ela falou uma história lúdica da vida dela lá que funcionou. [...] Às vezes quando ela não conseguia a atenção do pessoal que ela falava do cotidiano dela, essas coisas assim. Isso que eu achei legal. [...] O pessoal não presta atenção, tem que ter empatia também. [Estagiário 2, Momento Pré-regência, Pergunta a respeito das aulas da professora supervisora].

Além disso, o professor do subcampo escolar, sob a ótica dos estagiários entrevistados, age de maneira diferente daquela esperada do professor da universidade. Segundo os estagiários, o professor do subcampo da escola desenvolve uma interação de maior responsabilidade com os alunos. Essa responsabilidade é traduzida no sentido de dedicar mais cuidado e atenção ao aluno, além do estabelecimento de regras de comportamento, como se percebe na entrevista com a Estagiária 3:

E também eu acho que passa assim, das diferenças, por exemplo, da aula da graduação para a aula do Médio. Tipo, na graduação você não vai ficar, por exemplo, pedindo para o professor para sair da sala. Para usar o banheiro, não sei o que. E lá [na escola] é o professor que tem que cuidar de tudo: 'Posso encher minha garrafinha? Posso ir no banheiro? Posso não sei o que? Eu estou doente. Não sei o que, não sei o que.' Na graduação já é diferente. [...] O professor da escola precisa se preocupar com muito mais coisas que além de dar aula dele. Pedir silêncio, chamar a atenção. [Estagiária 3, Momento Préregência, Pergunta a respeito dos trabalhos dos professores dos subcampos escolar e universitário]. 


\section{Habitus do homo magister}

Um grupo desses bens simbólicos foi categorizado como disposições do habitus do Homo magister, termo proposto por Genovez (2008) para se referir ao professor da Educação Básica em contraposição ao Homo academicus utilizado por Bourdieu (2017) a respeito do professor universitário. Um fator percebido como eixo dessas disposições é a 'falta de tempo', que é, como afirma Edwards (1997, p. 37), "[...] um dos elementos estruturantes da realidade da sala de aula." Segundo esse entendimento, os professores elaboram estratégias para lidar com o tempo limitante, adequando a este o conteúdo escolar e outras atividades como a administração da lista de presença, a participação dos alunos na aula, a indisciplina dos alunos, entre outros.

Portanto, a falta de tempo é uma disposição desse habitus destacada com frequência pelos estagiários, que, a seu ver, necessitam levar em consideração e se adequar a ela, mesmo ainda como estagiários.

[...] eu queria não dar aula só expositiva. Só que ao mesmo tempo eu acabei fazendo as mesmas coisas porque eu reconheço que talvez ela [a professora 1] não quisesse ser assim. Mas ela acabou se adequando a isso por falta de tempo. [...] É a desvalorização. Se ela tivesse menos horas de trabalho, se fosse mais remunerada, não tivesse que fazer outras coisas ao mesmo tempo... [Estagiária 1, Momento Pós-regência, Pergunta sobre a professora supervisora e seu trabalho].

Há outras disposições desse habitus reconhecidas pelos estagiários como características próprias do professor do subcampo escolar e da escola na comparação com os professores do subcampo universitário. Estas se relacionam com a sua atuação na profissão: preparar aulas, desenvolvê-las, corrigir atividades, lidar com imprevistos e com diferentes situações ao mesmo tempo.

Porque lá na escola, por exemplo, que eu sei, é mais a parte de preparar, dar aula, corrigir. [...] $E$ lá é mais a parte mesmo da turma, ali. Assim, tem a parte lá das pedagogas e tal. Mas eu acho que é bem diferente mesmo. [...] Lá é mais voltado... Praticamente só voltado ali para dar aula, do que eu percebo. [Estagiária 3, Momento Pré-regência, Pergunta a respeito do trabalho dos professores dos subcampos universitário e escolar].

Com isso, percebe-se a centralidade dada à aula no entendimento dos estagiários a respeito da profissão docente da Educação Básica, revelando a ausência da percepção da ação docente para além de sala de aula, como o compartilhamento de conhecimento entre os pares, a produção de conhecimento, atividades administrativas na escola, relação com os pais dos alunos, atuação política em sindicatos e representações profissionais, entre outros. Atividades estas percebidas pelos estagiários como realizadas por seus professores do subcampo universitário. Ao mesmo tempo, são atividades que os professores supervisores reconhecem como pertencentes a sua atribuição (MELLO, 2019).

\section{Discussão: relações sobre o desenvolvimento profissional docente a partir dos julgamentos dos bens simbólicos}

O subcampo escolar e o subcampo da escola, como campos de produções simbólicas, possuem uma autonomia relativa (BOURDIEU, 1983) ou restrita (GENOVESE, 2014) na medida em que não se isolam na produção e na classificação dos bens 
simbólicos a respeito do seu subcampo. Segundo Bourdieu (2015, p. 106),

Pode-se medir o grau de autonomia de um campo de produção erudita com base no poder de que dispõe para definir as normas de sua produção, os critérios de avaliação de seus produtos e, portanto, para retraduzir e reinterpretar todas as determinações externas de acordo com seus princípios próprios de funcionamento.

Nesse sentido, pergunta-se: os subcampos das escolas do campo educacional brasileiro controlam o processo de julgamento dos bens simbólicos por ela produzidos?

Basta perceber o imaginário social a respeito do 'bom professor' ou do habitus do Homo magister para deduzir que os agentes do subcampo da escola não controlam o julgamento a respeito desses bens simbólicos, muitas vezes não condizentes com os bens simbólicos sobre a profissão produzidos e validados pelos professores em seu subcampo.

Em outras palavras, um 'bom professor' da Educação Básica é avaliado de forma diferente no subcampo da universidade e nos subcampos escolar e da escola. O reflexo dessa discrepância de julgamentos das produções simbólicas do subcampo da escola pode ser visto nas classificações desenvolvidas pelos estagiários nesta investigação.

Dessa forma, por meio dos agentes híbridos entre os subcampos da universidade e da escola percebe-se a relação de autonomia relativa (BOURDIEU, 1983) que se estabelece entre esses subcampos, principalmente no sentido do que é produzido pelo subcampo da escola e julgado pelo subcampo da universidade, tendo o estagiário como 'porta voz' para esse julgamento.

Assim, por exemplo, entre as atribuições do Homo magister, os estagiários não destacam a produção de conhecimento pelos agentes do subcampo da escola, produção que é percebida pelos professores supervisores e incentivada pelos subcampos da escola e escolar. Portanto, não há correspondência entre o que o professor do subcampo da escola compreende de seu trabalho e o identificado e classificado pelo estagiário como característico da atividade docente do subcampo da escola. E, portanto, por esse exemplo, aponta-se a ausência de autonomia plena desse subcampo.

Os julgamentos atribuídos pelos estagiários às produções culturais e simbólicas dos subcampos da escola e escolar remetem a compreensões, emissões de valores e posicionamentos a respeito da profissão docente da Educação Básica. Por um lado, se faz possível uma compreensão individualizada a respeito dos estagiários, estabelecendo, por exemplo, a relação de sua illusio ou a construção de seu habitus primário (construído na socialização familiar) com esses julgamentos. Por outro lado, esses julgamentos e seus referidos desdobramentos permitem inferir sobre o processo de DPD vivenciado até o momento, estimulado, principalmente, pelas vivências no curso de licenciatura. É dessa análise que o trabalho aqui desenvolvido se ocupa principalmente.

Nesse sentido, a partir da análise desses julgamentos se fez possível perceber quatro principais aspectos nesse fragmento do DPD (DAY, 2005) dos estagiários, que representa o estágio supervisionado: (1) A desvalorização das produções culturais e simbólicas dos subcampos escolar e da escola frente às do subcampo universitário; (2) A compreensão do professor desses subcampos como especialista técnico; (3) A desvalorização da profissão docente do subcampo escolar frente ao universitário e, 
consequentemente; (4) a desvalorização do subcampo escolar. Esses aspectos são desenvolvidos a seguir.

Há uma desvalorização do que é produzido nos subcampos escolar e da escola na medida em que por parte dos estagiários, por um lado, está ausente a percepção da atividade do professor do subcampo escolar para além de sala de aula e, por outro lado, uma supervalorização dos recursos didáticos, técnicas de ensino-aprendizagem e a atribuição da sala de aula como ponto central da profissão desse docente.

As atribuições das atividades desse professor de cuidado e atenção com os alunos e de estabelecimento de regras de comportamento também remetem a uma desvalorização desse professor. Essa desvalorização é presente nesses julgamentos uma vez que não se espera o mesmo do professor universitário e se relacionam ao cuidado paternal e, portanto, de um âmbito que escapa ao âmbito escolar.

Segundo Arroyo (2013), a escola é um campo que sofre intervenções de outros campos, inclusive o familiar, devido a esses significados que lhe são atribuídos, embora pertencentes às responsabilidades familiares e por não estar muito definido o limite entre os campos. Dessa forma, subvaloriza-se a profissão docente a partir do momento que não é compreendida como uma construção pedagógica, teórica, política e técnica, ou seja, uma profissão, e que, portanto, extrapola o cuidado e o afeto das relações familiares.

Mesmo que haja entre os colaboradores desta pesquisa a percepção de que a atividade docente vá além do conteúdo, para eles, ela se restringe à sala de aula, não existindo referência a uma produção de conhecimento, mas sim a regras de comportamento. Há uma diferenciação do trabalho do professor da universidade - a produção de conhecimento - que aparenta ignorar o que ocorre no trabalho docente da Educação Básica.

A desvalorização do conhecimento escolar e da atividade do professor do subcampo escolar também ocorre quando os estagiários analisam a relação dos alunos com o conhecimento escolar, classificando esse conhecimento como simplificado e obsoleto, sendo mais bem realizado de forma lúdica e não necessitando de maiores aprofundamentos do já proposto pelo livro didático.

Defende-se o professor do subcampo escolar brasileiro como um produtor de conhecimento e com ação que extrapola a sala de aula. Quando não há a percepção dessa produção e ações, por parte do estagiário, é realizada, ainda que de maneira não consciente, não intelectualizada e não explícita, uma tomada de posição: o professor do subcampo escolar é um reprodutor de conhecimento e não um produtor, sua ação é técnica e, portanto, toda a produção cultural e simbólica do subcampo escolar remete às técnicas de ensino e de aprendizagem aplicadas pelo professor.

Uma vez que a sociedade hierarquiza o trabalho intelectual sobre o técnico/ prático, a produção do professor do subcampo escolar, voltada, de acordo com os colaboradores desta pesquisa, para a técnica de ensino e de sala de aula, é subjugada à produção intelectual realizada no subcampo universitário.

De acordo com Contreras (2012), a relação que os professores estabelecem com o conhecimento, além de outras atribuições da profissão, permitem a sua classificação em diferentes modelos de professor. Assim, de acordo com a classificação proposta pelo autor, o modelo de professor percebido pelos estagiários é condizente ao de Especialista Técnico (CONTRERAS, 2012). Nesse sentido, reflete-se que 
Os docentes, como experts do ensino, não dispõem em princípio das habilidades para a elaboração das técnicas, mas apenas para sua aplicação. A separação hierarquizada entre pesquisadores e técnicos supõe uma dependência dos segundos com relação aos primeiros, bem como uma subordinação às condições implícitas do conhecimento técnico, enquanto meios para conseguir determinados fins, não se abrindo à disputa sobre os fins desejáveis, mas tão somente à aceitação daqueles para os quais as técnicas estão concebidas. Deste modo, os professores não só assumem uma dependência em relação a um conhecimento prévio que não elaboram, como também à sua finalidade (CONTRERAS, 2012, p. 106).

Portanto, conforme o julgamento da atividade docente como instrumentalização técnica, projeta-se a profissão docente como Especialista Técnico. E, assim, há a hierarquização tanto dos conhecimentos produzidos pelos subcampos escolares e universitários quanto entre as profissões desses dois subcampos. Da mesma forma, os trechos de entrevistas com os estagiários aqui destacados sugerem existir uma tensão implícita entre os subcampos, refletida nos julgamentos dos bens simbólicos do subcampo da escola em contraposição ao do subcampo universitário. Tensão essa que remete a uma relação de violência simbólica, uma vez que trabalha sob a subvalorização dos subcampos escolar e da escola no que diz respeito à sua profissão e suas produções simbólicas, como discutido anteriormente.

Além disso, os estagiários na Licenciatura são preparados para sua atuação enquanto professores do subcampo escolar, esperando-se que se insiram nesse subcampo. Assim, uma vez que atribuem esse julgamento a sua própria futura profissão e a seu futuro subcampo, estão de acordo (de forma não consciente, não intelectualizada e não explícita) com essa subvalorização difundida no subcampo universitário e com o arbitrário cultural (BOURDIEU; PASSERON, 2012) imposto a respeito do subcampo escolar.

\section{Considerações finais}

O estágio supervisionado sob o tipo de parceria dirigida (FOERSTE, 2005) entre os subcampos em que, majoritariamente, não é planejado de forma colaborativa pelos mesmos, representa, ainda, o principal momento formativo no DPD do professor, no qual ele tem expressamente objetivada a profissão da Educação Básica. Esse mesmo estágio, sob essa parceria, é, portanto, uma construção do subcampo universitário (BRASIL, 2019), com seus habitus, leis e capitais distintos ao do subcampo para o qual pretende preparar os estagiários.

Em consequência disso, a profissão do docente do subcampo escolar no DPD durante o estágio supervisionado é confrontada por entendimentos, lógicas e bens simbólicos não pertencentes a esse subcampo. Assim, os estagiários não vivenciam a centralidade que a profissão docente da Educação Básica deveria ter nesse momento formativo. Confronta-se com outros bens simbólicos, os classificam, julgam, hierarquizam, distanciando, nos âmbitos cultural e simbólico, o estágio do objetivo de preparar profissionais para o subcampo escolar.

Nesse sentido, é importante a proposta de Nóvoa (2017) de retomar a centralidade da profissão docente nos processos de formação de professores. Nessa perspectiva, aproxima-se, também, ao entendimento dessa formação e do estágio supervisionado, em específico, como um momento de DPD, no qual a profissão está em primeiro plano. 
Conclui-se, dessa forma, que os julgamentos realizados pelos estagiários extrapolam a escola e refletem um posicionamento entre os subcampos educacionais, revelando uma relação de violência simbólica (BOURDIEU; PASSERON, 2012) entre as profissões do Ensino Superior e da Educação Básica e entre os subcampos. Nesse sentido, também está implícita uma relação de divisão de trabalho: entre o trabalho intelectual e o prático. Este subjugado àquele, assim como os que os desenvolvem, ou seja, o professor do subcampo escolar subjugado ao professor do subcampo universitário.

O estágio supervisionado nas licenciaturas tem um significado importante no DPD (DAY, 2005) dos futuros professores do subcampo escolar como oportunidade de uma vivência do subcampo da escola sob o ponto de vista da docência. Como visto, é o momento no qual também os estagiários se deparam com as produções culturais e simbólicas de dois subcampos relacionados à profissão docente e por meio desse contato elaboram seus julgamentos sobre os mesmos.

Com os resultados desta investigação, percebe-se, portanto, a importância que o estágio representa no trabalho sobre essas concepções e julgamentos, buscando a superação de um entendimento a respeito da docência da Educação Básica subjugada à docência do Ensino Superior. Assim, seria importante, dentre diversas ações, que os cursos de licenciatura fomentassem vivências nos estágios que extrapolem a sala de aula, para que os futuros professores percebam sua profissão como produtora de conhecimento, seu futuro campo como produtor de bens simbólicos essenciais para nossa Educação, valorizando assim a profissão docente do subcampo escolar e esse subcampo. Da mesma forma, a parceria colaborativa (FOERSTE, 2005) entre os subcampos para a formação docente inicial deve ser buscada para a possibilidade de relações menos pautadas na violência simbólica institucionalizada entre os subcampos e suas profissões.

\section{Agradecimentos}

Agradecemos aos professores e estagiários colaboradores desta pesquisa; ao Programa de Pós-Graduação e à Coordenação de Aperfeiçoamento de Pessoal de Nível Superior (CAPES) pela bolsa de doutoramento concedida.

\section{Referências}

AGUIAR, A. I. Illusio. In: CATANI, A. M.; NOGUEIRA, M. A.; HEY, A. P.; MEDEIROS, C. C. C. (org.). Vocabulário Bourdieu. Belo Horizonte: Autêntica, 2017. p. 231-233.

AROEIRA, K. P. Estágio supervisionado e possibilidades para uma formação com vínculos colaborativos entre a universidade e a escola. In: ALMEIDA, M. I.; PIMENTA, S. G. (org.). Estágios supervisionados na formação docente: educação básica e educação de jovens e adultos. São Paulo: Cortez, 2014. p. 113-152.

ARROYO, M. Ofício de mestre: imagens e auto-imagens. 15. ed. Petrópolis: Vozes, 2013.

BOURDIEU, P. Algumas propriedades dos campos. In: BOURDIEU, P. Questões de sociologia. Rio de Janeiro: Marco Zero, 1983. p. 89-94.

BOURDIEU, P. Compreender. In: BOURDIEU, P. A miséria do mundo. Petrópolis: Vozes, 2001. p. 693732. 
BOURDIEU, P. Homo academicus. 2. ed. Florianópolis: Ed. da UFSC, 2017.

BOURDIEU, P. O mercado de bens simbólicos. In: BOURDIEU, P. A economia das trocas simbólicas. 8. ed. São Paulo: Perspectiva, 2015. p. 99-182.

BOURDIEU, P. O poder simbólico. Lisboa: Difel, 2003.

BOURDIEU, P.; PASSERON, J. C. A reprodução: elementos para uma teoria do sistema de ensino. 5. ed. Petrópolis: Vozes, 2012.

BRASIL. Lei 5.692, de 11 de agosto de 1971. Fixa diretrizes e bases para o ensino de $1^{\circ}$ e $2^{\circ}$ graus, e dá outras providências. Brasília: Presidência da República, 1971. Disponível em: https://cutt.ly/ ZW62n6g. Acesso em: 19 jun. 2021.

BRASIL. Lei no 11.788, de 25 de setembro de 2008. Brasília: Presidência da República, 2008. Disponível em: https://cutt.ly/sW62Kzd. Acesso em: 19 jun. 2021.

BRASIL. Conselho Nacional de Educação. Resolução CNE/CP n० 2, de 20 de dezembro de 2019. Brasília: MEC, 2019. Disponível em: https://cutt.ly/ZW62MuF. Acesso em: 19 de jun. de 2020.

CALDERANO, M. A. O estágio curricular e a docência compartilhada: na perspectiva do realismo crítico. Curitiba: Appris, 2017.

CHANTRAINE-DEMAILLY, L. Modelos de formação contínua e estratégias de mudança. In: NÓVOA, A. Os professores e a sua formação. Lisboa: Publicações Dom Quixote: Instituto de Inovação Educacional, 1995. p. 139-158.

CONTRERAS, J. D. A autonomia de professores. São Paulo: Cortez, 2012.

DAY, C. Formar docentes: cómo, cuándo y en qué condiciones aprende el profesorado. Madrid: Narcea, 2005.

EDWARDS, V. Os sujeitos no universo da escola: um estudo etnográfico no ensino primário. São Paulo: Ática, 1997.

FIORENTINI, D.; CRECCI, V. Desenvolvimento profissional docente: um termo guarda-chuva ou um novo sentido à formação? Formação Docente, Belo Horizonte, v. 5, n. 8, p. 11-23, 2013. Disponível em: https://cutt.ly/IW69JJD. Acesso em: 19 de jun. de 2020.

FOERSTE, E. Parceria na formação de professores. São Paulo: Cortez, 2005.

GENOVESE, L. G. R. Os graus de autonomia das práticas dos professores de física: relações entre os subcampos educacionais brasileiros. In: CAMARGO, S.; GENOVESE, L. G. R; DRUMMOND, J. M. H. F.; QUEIROZ, G. R. P. C; NICOT, Y. E.; NASCIMENTO, S. S. (org.). Controvérsias na pesquisa em ensino de física. São Paulo: Livraria da Física, 2014. p. 61-88.

GENOVESE, L. G. R.; CASTILHO, D. D.; QUEIROZ, J. R. O. Incorporação do habitus de homo magister no interior do estágio colaborativo em física: um olhar sobre a relação entre professor supervisor e estagiário. Ensino em Re-Vista, Uberlândia, v. 22, n. 2, p. 311-331, 2015. DOI: https://doi.org/ gv6d.

GENOVEZ, L. G. R. Homo magister: conhecimento e reconhecimento de uma professora de ciências pelo campo escolar. 2008. 228 f. Tese (Doutorado em Ensino de Ciências) - Faculdade de Ciências, Universidade Estadual Paulista, Bauru, 2008. Disponível em: https://cutt.ly/JW6twZt. Acesso em: 15 set. 2015.

LAHIRE, B. Reprodução ou prolongamentos críticos? Educação \& Sociedade, Campinas, v. 23, n. 78, p. 37-55, 2002. DOI: https://doi.org/dtgnfp.

LESSARD-HÉBERT, M.; GOYETTE, G.; BOUTIN, G. Investigação qualitativa: fundamentos e práticas. 5. ed. Lisboa: Instituto Piaget, 2012. 
LIMA, M. S. L. Estágio e aprendizagem da profissão docente. Brasília: Liber Livro, 2012.

MAUGER, G. Violência simbólica. In: CATANI, A. M.; NOGUEIRA, M. A.; HEY, A. P.; MEDEIROS, C. C. C (org.). Vocabulário Bourdieu. Belo Horizonte: Autêntica Editora, 2017. p. 359-361.

MARCELO GARCIA, C. Formação de professores para uma mudança educativa. Porto: Porto Editora, 1999.

MELLO, A. C. R. Desenvolvimento profissional do professor supervisor de estágio durante a socialização com os estagiários de ciências biológicas. 2015. Dissertação (Mestrado em Educação) - Universidade Federal do Paraná, Curitiba, 2015. Disponível em: http://hdl.handle. net/1884/42790. Acesso em: 7 out. 2021.

MELLO, A. C. R. Relações de poder na formação docente: julgamentos dos bens simbólicos do subcampo escolar durante o estágio supervisionado. 2019. Tese (Doutorado em Educação)

- Universidade Federal do Paraná, Curitiba, 2019. Disponível em: https://hdl.handle. net/1884/66887. Acesso em: 7 out. 2021.

MELLO, A. C. R.; HIGA, I. Busca por capitais no campo da escola e sua relação com o desenvolvimento profissional docente de professores supervisores de estágio de ciências e biologia. Ciência \& Educação, Bauru, v. 24, n. 2, p. 301-317, 2018. DOl: https://doi.org/gv6t.

NÓVOA, A. Firmar a posição como professor, afirmar a profissão docente. Cadernos de Pesquisa, São Paulo, v. 47, n. 166, p. 1106-1133, 2017. DOI: https://doi.org/gv6v.

PASSIANI, E.; ARRUDA, M. A. N. Campo cultural. In: CATANI, A. M.; NOGUEIRA, M. A.; HEY, A. P.; MEDEIROS, C. C. C. (org.). Vocabulário Bourdieu. Belo Horizonte: Autêntica, 2017.

PEREIRA, J. E. D. Relações de poder no interior do campo universitário e as licenciaturas. Cadernos de Pesquisa, São Paulo, n. 111, p. 183-201, 2000. DOI: https://doi.org/bcwdsr.

PIMENTA, S. G. O estágio na formação de professores: unidade, teoria e prática? 7. ed. São Paulo: Cortez, 2006.

SAVIANI, D. Pedagogia: o espaço da educação na universidade. Cadernos de Pesquisa, São Paulo, v. 37, n. 130, p. 99-134, 2007.

VAILLANT, D.; MARCELO GARCIA, C. Ensinando a ensinar: as quatro etapas de uma aprendizagem. Curitiba: Ed. UTFPR, 2012. 